\title{
Amplified Fragment Length Polymorphism Analysis and Internal Transcribed Spacer and coxII Sequences Reveal a Species Boundary Within Pythium irregulare
}

\author{
Carla D. Garzón, David M. Geiser, and Gary W. Moorman
}

Department of Plant Pathology, Pennsylvania State University, University Park 16802.

Accepted for publication 26 August 2005.

\begin{abstract}
Garzón, C. D., Geiser, D. M., and Moorman, G. W. 2005. Amplified fragment length polymorphism analysis and internal transcribed spacer and coxII sequences reveal a species boundary within Pythium irregulare. Phytopathology 95:1489-1498.

Pythium irregulare is a plant-pathogenic oomycete that causes significant damage to a variety of crops, including ornamentals and vegetables. Morphological as well as molecular studies have reported high levels of genetic diversity within $P$. irregulare sensu lato which has raised the question as to whether it is a single species or is actually a complex of morphologically similar (cryptic) species. In this study, we used amplified fragment length polymorphism (AFLP) fingerprinting and DNA sequence analysis of the internal transcribed spacer (ITS) region of the

sequence of a $P$. irregulare neotype at the CBS collection as well as ITS and coxII sequences for $P$. irregulare, $P$. spinosum, and $P$. sylvaticum from previous studies were included in our analysis. Cluster analysis identified a 19-isolate group (IR-II) that separated itself from the rest of the sample (IR-I). Population structure and sequence analyses supported the distinction of IR-I and IR-II and identified IR-II as $P$. irregulare sensu stricto. IR-I was designated Pythium sp. clade IR-I. Two insertion/deletion mutations and nine nucleotide substitutions in the ITS region and three in the sequence of coxII and the adjacent spacer region separated the two species. Additionally, they differed significantly $(P>0.01)$ in the frequency of 182 (77\%) AFLP alleles. Gene flow results suggested that P. irregulare sensu stricto and Pythium sp. clade IR-I are cryptic species capable of exchanging favorable alleles $(\mathrm{Nm}=0.72)$.
\end{abstract} ribosomal genes (ITS region) and a portion of the mitochondrial cytochrome oxidase II gene and the spacer region between coxI and coxII to characterize 68 isolates of $P$. irregulare from the United States. The ITS
Additional keywords: cryptic speciation, damping-off, diagnostic fingerprints, genetic marker, Pythium root rot.
Pythium irregulare Buisman (kingdom Stramenopila, phylum Oomycota) is a ubiquitous plant-pathogenic species with multiple and diverse hosts. It causes pre- and postemergence damping-off of seedlings, root rots, and blackleg of several crops including Triticum, Solanum, Pisum, Citrus, Saccharum, Rhododendron, Chrysanthemum, and Pelargonium $(9,26)$. In the United States, there is an increased concern about these diseases due to recently detected resistance to mefenoxam (enantiomer of metalaxyl) and propamocarb $(1,26,27)$ in $P$. irregulare.

Management of plant diseases requires accurate and timely identification of pathogens. Fungicide treatment is often recommended when Pythium propagules are found in diseased plant material, regardless of the species. More accurate diagnosis of species could reduce wasteful use of resources because, while some Pythium species are aggressive, others are weak plant pathogens, and others are pathogens of fungi and can actually be beneficial (5). Fungicide applied to control all species is wasteful and may leave the crop more vulnerable to disease. Furthermore, resistance to mefenoxam or propamocarb fungicides has been detected in several Pythium species $(26,27)$. Accurate knowledge of the pathogen present in a crop will allow growers to implement disease management strategies that effectively use the resources available to them.

Pythium species are difficult to identify because they have few variable morphological characters. $P$. irregulare sensu lato (s.l. = in the broad sense), in particular, represents a challenge because

Corresponding author: C. D. Garzón; E-mail address: cdg143@psu.edu

DOI: 10.1094/PHYTO-95-1489

(c) 2005 The American Phytopathological Society of its variable oogonial morphology $(36,37)$ ranging from smooth to having blunt conical or finger-like projections of variable length. Ornamented and smooth-spherical oogonia can be found in the same isolate. Oogonia can be globose to irregular, 16 to $21 \mu \mathrm{m}$ diameter, intercalary, or terminal. Antheridia originate at some distance from the oogonial stalk, but there are members of the species with sessile or hypogynous antheridia as well (36).

To facilitate identification, a variety of biochemical and molecular biology methods $(3,13,20,25,39)$ have been adapted to $P y$ thium species. These studies have also revealed that $P$. irregulare s.l. has high levels of intraspecific genetic diversity. Every study has identified two or more protein, DNA fragment patterns, or DNA sequences for this morphological species. Protein analyses allowed differentiation among several Pythium species; however, their effectiveness in separating closely related species was not good. Serological profiling using mono- and polyclonal antibodies (39) produced two markedly different patterns of reactivity for $P$. irregulare, but could not effectively distinguish between $P$. irregulare and P. sylvaticum. A study of 10 Pythium species using polymorphisms in 13 isozymes reported that $62 P$. irregulare isolates divided into three clusters that tightly overlapped with two $P$. spinosum clusters, leading to the conclusion that these two species were indistinguishable based on isozyme polymorphisms (7). Barr et al. (4) compared the isozyme-based genetic diversity (11 isozyme loci), morphological characters, and growth rate of $125 \mathrm{P}$. irregulare isolates from diverse locations and hosts around the world and distinguished 33 multilocus genotypes that formed two taxonomically distinct groups. DNA-based methods have easily distinguished $P$. irregulare s.l. from other species. Intraspecific genetic variation has been detected using DNA sequencing of the ribosomal DNA internal transcribed spacers (ITS 
region) and the cytochrome oxidase II gene (coxII), and DNA fingerprinting (random amplified polymorphic DNA [RAPD] and amplified fragment length polymorphism [AFLP]) analyses $(3,13$, $25)$. Two independent phylogenetic studies $(19,22)$ on the genus Pythium identified two clades in P. irregulare, based on DNA sequences of nuclear and mitochondrial genes. Matsumoto et al. (24) analyzed 47 isolates of $P$. irregulare from diverse geographical origins and hosts, using morphological characteristics of the oogonia and oospore, ITS sequences, ITS restriction fragment length polymorphism (RFLP), and RAPD analysis using seven arbitrary primers. They observed four divisions within $P$. irregulare (I to IV) supported by RAPD and ITS sequence analysis. Garzón et al. (13) identified diagnostic-AFLP fingerprints for nine $P y$ thium species and assessed the genetic diversity of $P$. aphanidermatum, $P$. ultimum, and $P$. irregulare. Two main groups were identified within a sample of $20 P$. irregulare isolates mostly from the United States, each having its own distinctive AFLP fingerprint.

From a phytopathological perspective, the great diversity within $P$. irregulare s.l. represents a diagnostic and management challenge. If the variability can be characterized as population structure, identification of the factors associated with it may provide useful information for the management of diseases caused by this pathogen. For example, if the population structure in greenhouse crops is determined by geographic origin, then disease management strategies should aim at preventing the introduction of the pathogen into production areas from movement of soil, water, or plants from the facility or its surroundings. If the population structure is associated with host, then control measures should focus on movement of plant material in and out of production areas. However, if the population structure is a result of a speciation process, then each group should be studied as an individual species to avoid misinterpretation of the data. Although intraspecific division of $P$. irregulare s.l. has been reported in the literature repeatedly $(4,7,13,19,22)$, the depth of this division and its repercussion in the management of the pathogen are still unclear.

In this study, we used DNA sequence analysis of the ITS region (including the 5.8S ribosomal RNA gene) of the nuclear ribosomal genes and a partial sequence of the mitochondrial cytochrome oxidase II gene and the adjacent spacer region between coxI and coxII, and whole genome AFLPs to characterize $P$. irregulare s.l. isolates from diverse hosts and geographic areas within the United States, with and without resistance to mefenoxam.

TABLE 1 . Isolates analyzed in this investigation

\begin{tabular}{|c|c|c|c|c|c|c|c|}
\hline $\begin{array}{l}\text { Collection } \\
\text { designation }\end{array}$ & Species & ITS $^{\mathrm{a}}$ & $\operatorname{cox}^{\mathrm{a}}$ & Metalaxyl ${ }^{\mathrm{b}}$ & Host & Year & Origin \\
\hline $\mathrm{P} 15$ & P. irregulare & AY907892 & $\mathrm{c}^{\mathrm{c}}$ & - & Euphorbia pulcherrima & 1995 & PA \\
\hline $\mathrm{P} 25$ & P. irregulare & - & - & $\mathrm{R}$ & Euphorbia pulcherrima & 1997 & PA \\
\hline P31 & P. irregulare & - & - & $\mathrm{R}$ & Chrysanthemum & 1998 & PA \\
\hline P37 & P. irregulare & - & - & $\mathrm{R}$ & Ranunculus & 1999 & PA \\
\hline P39 & P. irregulare & - & - & $\mathrm{S}$ & Pelargonium & 1999 & PA \\
\hline P50 & P. irregulare & AY907893 & AY907918 & $\mathrm{S}$ & Euphorbia pulcherrima & 1999 & PA \\
\hline P54 & P. irregulare & - & - & $\mathrm{R}$ & Pulmonaria & 2000 & PA \\
\hline P55 & P. irregulare & - & - & $\mathrm{R}$ & Cordyline & 2000 & PA \\
\hline P56 & P. irregulare & - & - & $\mathrm{R}$ & Chrysanthemum & 2000 & PA \\
\hline P57 & P. irregulare & AY907894 & - & $\mathrm{R}$ & Bocopa & 2000 & PA \\
\hline $1103-81$ & P. irregulare & AY907895 & AY907919 & $\mathrm{S}$ & Crassula & 1981 & PA \\
\hline $2076-80$ & P. irregulare & AY907907 & AY907932 & $\mathrm{S}$ & Capsicum апnиит & 1980 & PA \\
\hline 22009-99 & P. irregulare & - & - & $\mathrm{S}$ & Thymus & 1999 & PA \\
\hline $22164-98$ & P. irregulare & - & - & $\mathrm{S}$ & Cyclamen & 1998 & PA \\
\hline 31074-99 & P. irregulare & - & - & - & Catharanthus & 1989 & PA \\
\hline $42130-97$ & P. irregulare & AY907896 & AY907944 & $\mathrm{S}$ & Pelargonium & 1997 & PA \\
\hline 42143-99 & P. irregulare & AY907897 & AY907920 & $\mathrm{S}$ & Pelargonium & 1999 & PA \\
\hline 42144-99 & P. irregulare & AY907898 & AY907925 & $\mathrm{S}$ & Pelargonium & 1999 & PA \\
\hline $42145-99$ & P. irregulare & - & - & $\mathrm{S}$ & Pelargonium & 1999 & PA \\
\hline $45021-97$ & P. irregulare & - & - & $\mathrm{R}$ & Sedum & 1997 & PA \\
\hline $52066-96$ & P. irregulare & - & - & $\mathrm{S}$ & Pelargonium $\times$ hortorum & 1996 & PA \\
\hline $6028-80$ & P. irregulare & - & AY907931 & - & Capsicum annuum & 1980 & PA \\
\hline $61186-84$ & P. irregulare & - & - & - & Malus & 1984 & PA \\
\hline $63067-99$ & P. irregulare & - & - & $\mathrm{R}$ & Pelargonium $\times$ hortorum & 1999 & PA \\
\hline $63105-99$ & P. irregulare & - & - & $\mathrm{R}$ & Heuchera & 1999 & PA \\
\hline $63108-98$ & P. irregulare & - & AY907933 & $\mathrm{S}$ & Schlumberger & 1998 & PA \\
\hline $63108-99$ & P. irregulare & AY907908 & AY907934 & $\mathrm{S}$ & Aquilegia & 1999 & PA \\
\hline $72076-96$ & P. irregulare & AF452142 & AY907945 & $\mathrm{S}$ & Euphorbia pulcherrima & 1996 & PA \\
\hline $73028-97$ & P. irregulare & AY907909 & AY907936 & $\mathrm{S}$ & Euphorbia pulcherrima & 1997 & PA \\
\hline $80171-91$ & P. irregulare & AY907899 & AY907921 & - & Taxus & 1991 & PA \\
\hline $81271-97$ & P. irregulare & - & - & $\mathrm{S}$ & Sedum & 1997 & PA \\
\hline $81758-98$ & P. irregulare & AY907910 & AY907929 & $\mathrm{S}$ & Ocimum basilicum & 1998 & PA \\
\hline $81774-98$ & P. irregulare & AY907900 & AY907928 & $\mathrm{S}$ & Euphorbia pulcherrima & 1998 & PA \\
\hline 325393 & P. irregulare & AY907901 & AY907926 & $\mathrm{S}$ & Anigozanthus & - & Australia \\
\hline 346955 & P. irregulare & - & - & - & Gypsophila & 1991 & Israel \\
\hline $363670 \mathrm{R}$ & P. irregulare & AY907911 & AY907930 & $\mathrm{S}$ & Allium & - & Taiwan \\
\hline $371142 \mathrm{R}$ & P. irregulare & - & - & - & Gerbera & - & Italy \\
\hline $371144 \mathrm{R}$ & P. irregulare & AF452141 & - & - & Basilicum & - & Italy \\
\hline $13-1$ & P. irregulare & - & - & - & Pelargonium & - & MI \\
\hline $13-7$ & P. irregulare & AY907912 & AY907937 & $\mathrm{S}$ & Pelargonium & - & MI \\
\hline $13-10$ & P. irregulare & AY907913 & AY907940 & - & Pelargonium & - & MI \\
\hline & & & & & & \multicolumn{2}{|c|}{ (Continued on following page) } \\
\hline
\end{tabular}

a GenBank accession numbers of internal transcribed spacer (ITS) region and coxII gene-spacer region sequences.

${ }^{\mathrm{b}}$ Metalaxyl sensitivity: $\mathrm{S}=$ sensitive, $50 \%$ effective dose $\left(\mathrm{ED}_{50}\right)<100 \mu \mathrm{g} / \mathrm{ml} ; \mathrm{R}=$ resistant, $\mathrm{ED}_{50}>100 \mu \mathrm{g} / \mathrm{ml}$.

c - Indicates information not available.

${ }^{\mathrm{d}}$ Isolates from Matsumoto et al. (24).

e Partial coxI-II gene cluster sequences provided by F. Martin. 
Population structure and gene flow analyses among populations were performed to characterize intraspecific divisions and assess the level of separation among them.

\section{MATERIALS AND METHODS}

Isolates. Sixty-eight isolates morphologically identified as $P$. irregulare s.1. (36) of known location of origin, host, and/or year of isolation were studied (Table 1). One P. ultimum isolate was included as the outgroup for AFLP analysis. These isolates were stored at room temperature at The Pennsylvania State University in pieces of water agar in vials containing sterile tap water. For DNA extraction, isolates were grown on potato dextrose agar for 1 day and transferred to 4-cm-diameter petri dishes with $3 \mathrm{ml}$ of $20 \%$ V8 broth, and grown for 3 to 7 days at $23^{\circ} \mathrm{C}$ in the dark. Mycelial masses were harvested using a Buchner funnel and rinsed with distilled water. Each mycelial mass was then transferred to 2-ml centrifuge tubes and freeze-dried. Dehydrated mycelia were weighed and stored at $-20^{\circ} \mathrm{C}$ until used.

DNA purification. DNA was purified from approximately $100 \mu \mathrm{g}$ of dehydrated mycelium using Qiagen DNeasy Plant Mini Kits (Qiagen, Valencia CA), according to the manufacturer instructions, with the exception that mycelia were macerated at room temperature in lysis buffer with $1.5-\mathrm{ml}$ microcentrifuge tubes, micro-pestles, and sterile quartz sand. DNA concentration was estimated using 1.5\% agarose gels and $4 \mu \mathrm{l}$ of High DNA Mass Ladder (Invitrogen Life Technologies, Carlsbad, CA). DNA purity was assessed by measuring the nucleic acid/protein absorbance ratio with a spectrophotometer.

AFLP analysis. Restriction-ligation and preselective reactions were performed as described previously (13). Eight selective EcoRI/MseI primer combinations were tested. All primers were obtained from PE Applied Biosystems (Foster City, CA). AFLP fragments were analyzed in an ABI 3100 automated capillarity system, using GeneScan Analysis Software (Applied Biosystems). Three selective primer combinations were selected (Mse I+C/ $E c o \mathrm{RI}+\mathrm{AG}-\mathrm{VIC}, M s e \mathrm{I}+\mathrm{C} / E c o \mathrm{RI}+\mathrm{CC}-\mathrm{FAM}$, and $M s e \mathrm{I}+\mathrm{C} / E c o \mathrm{RI}+$ CG-VIC) based on the high number of polymorphic markers and the intensity of fragment peaks. Data were imported to Microsoft Excel, and fragments were aligned by size manually or using a program in the SAS system (SAS Institute, Cary, NC) and visually verified to prevent possible errors. Markers with low mean peak amplitude relative to noise were eliminated to avoid ambiguities. Data were transformed into a binary database, scoring presence and absence of markers as 1 or 0 , respectively. AFLP markers were assumed to represent one locus each and were treated as such during the analyses. Loci with alleles found in three or fewer isolates were eliminated to reduce homoplasy.

TABLE 1. (Continued from preceding page)

\begin{tabular}{|c|c|c|c|c|c|c|c|}
\hline $\begin{array}{l}\text { Collection } \\
\text { designation }\end{array}$ & Species & ITS $^{\mathrm{a}}$ & $\operatorname{cox}^{a}$ & Metalaxyl $^{\mathrm{b}}$ & Host & Year & Origin \\
\hline $13-12$ & P. irregulare & AY907902 & AY907942 & $\mathrm{S}$ & Pelargonium & - & $\mathrm{NY}$ \\
\hline $13-13$ & P. irregulare & AY907914 & AY907941 & - & Pelargonium & - & NY \\
\hline $13-14$ & P. irregulare & - & - & - & Pelargonium & - & NY \\
\hline $13-18$ & P. irregulare & - & - & - & Pelargonium & - & $\mathrm{CA}$ \\
\hline $13-21$ & P. irregulare & - & - & - & Pelargonium & - & $\mathrm{CA}$ \\
\hline $13-22$ & P. irregulare & AY907903 & AY907943 & $\mathrm{R}$ & Pelargonium & - & $\mathrm{CA}$ \\
\hline $13-24$ & P. irregulare & - & - & - & Pelargonium & - & $\mathrm{AL}$ \\
\hline $13-29$ & P. irregulare & AY907915 & AY907938 & $\mathrm{S}$ & Pelargonium & - & $\mathrm{OK}$ \\
\hline $13-30$ & P. irregulare & AY907916 & AY907939 & $\mathrm{S}$ & Pelargonium & - & $\mathrm{OK}$ \\
\hline $13-32$ & P. irregulare & AY907904 & AY907922 & $\mathrm{S}$ & Pelargonium & - & $\mathrm{CT}$ \\
\hline $13-33$ & P. irregulare & - & - & - & Pelargonium & - & $\mathrm{CT}$ \\
\hline $13-43$ & P. irregulare & - & - & - & Pelargonium & - & - \\
\hline $13-44$ & P. irregulare & - & - & - & Pelargonium & - & NY \\
\hline $13-45$ & P. irregulare & - & - & - & Pelargonium & - & MI \\
\hline $13-47$ & P. irregulare & - & - & - & Pelargonium & - & MI \\
\hline $13-48$ & P. irregulare & - & - & - & Pelargonium & - & MI \\
\hline $13-50$ & P. irregulare & - & - & - & Pelargonium & - & MI \\
\hline $13-56$ & P. irregulare & AY907905 & AY907923 & $\mathrm{R}$ & Pelargonium & - & FL \\
\hline $13-57$ & P. irregulare & - & AY907927 & $\mathrm{S}$ & Pelargonium & - & $\mathrm{FL}$ \\
\hline $13-58$ & P. irregulare & AY907906 & AY907924 & - & Pelargonium & - & FL \\
\hline $13-59$ & P. irregulare & AY907917 & AY907935 & - & Pelargonium & - & FL \\
\hline $4 \mathrm{I}$ & P. irregulare & - & - & $\mathrm{R}$ & Soil & 2000 & PA \\
\hline $5 \mathrm{I}$ & P. irregulare & - & - & $\mathrm{R}$ & Soil & 2000 & PA \\
\hline $6-1 \mathrm{I}$ & P. irregulare & - & - & $\mathrm{R}$ & Soil & 2000 & PA \\
\hline $8 \mathrm{I}$ & P. irregulare & - & - & $\mathrm{R}$ & Soil & 2000 & PA \\
\hline P62 & P. irregulare & - & - & $\mathrm{S}$ & Soil & 2000 & PA \\
\hline P64 & P. irregulare & - & - & $\mathrm{S}$ & Soil & 2000 & PA \\
\hline ATCC 32231 & P. ultimum & AF452160 & - & $\mathrm{S}$ & Phaseolus & - & USA \\
\hline CBSnr 733.94 & P. irregulare & AY598702 & - & - & - & - & - \\
\hline UOP359 & P. irregulare & AB 108005 & - & - & - & - & - \\
\hline MAFF305572d & P. irregulare & AB107999 & - & - & - & - & - \\
\hline $\mathrm{EP}-2^{\mathrm{d}}$ & P. irregulare & AB107997 & - & - & - & - & - \\
\hline ATCC $42912^{\mathrm{d}}$ & P. irregulare & AB107996 & - & - & - & - & - \\
\hline $74-22^{d}$ & P. irregulare & AB107995 & - & - & - & - & - \\
\hline Point $B^{d}$ & P. irregulare & AB 108000 & - & - & - & - & - \\
\hline K6- $2^{\mathrm{d}}$ & P. irregulare & AB107998 & - & - & - & - & - \\
\hline Py63 & P. irregulare & AB 108003 & - & - & - & - & - \\
\hline Py $26^{d}$ & $P$. irregulare & AB108001 & - & - & - & - & - \\
\hline Py61 ${ }^{d}$ & P. irregulare & AB108002 & - & - & - & - & - \\
\hline Py64 & P. irregulare & AB108004 & - & - & - & - & - \\
\hline OM $121^{d}$ & P. sylvaticum & AJ233459 & - & - & - & - & - \\
\hline $\mathrm{OD} 231^{\mathrm{d}}$ & P. spinosum & AJ233457 & - & - & - & - & - \\
\hline ATCC $96201^{\mathrm{e}}$ & P. irregulare & - & AF196602 & - & Panax & - & Korea \\
\hline ATCC $96946^{\mathrm{e}}$ & P. sylvaticum & - & AF196624 & - & Soil & - & Korea \\
\hline $79-4^{e}$ & P. spinosum & - & AF196616 & - & Soil & - & FL \\
\hline
\end{tabular}


The data matrix was deposited in TreeBASE (accession no. S1336-M2350).

Cluster analysis. Two genetic distance methods were used to analyze the sample for internal clusters. First, total distances between individual AFLP genotypes were calculated and trees were constructed by the unweighted pair-group method with arithmetic average (UPGMA) algorithm using PAUP version 4.0b 10 (Sinauer Associates, Inc., Sunderland, MA). Tree branch stability was assessed by bootstrap analysis with 1,000 repetitions. Second, Jaccard's distances were calculated and a neighbor-joining (NJ) phenogram was constructed using NTSYS version 2.02j (Exeter Software, Setauket, NY).

Population subdivision and gene flow analysis. Two hundred thirty-six bands with an observed frequency of less than $1-(3 / N)$ were included in the analysis (21). To determine the genetic differentiation among populations, Nei's gene diversity statistics (28), namely total gene diversity $\left(H_{T}\right)$, genetic diversity within populations $\left(H_{S}\right)$, the proportion of the total diversity among populations $\left(G_{S T}\right)$, and the average number of migrants between populations per generation $(\mathrm{Nm})(31)$ were estimated using POPGENE (Exeter Software). POPGENE calculated allele frequencies considering AFLP fragments as dominant markers, assuming each fragment represents a single locus. Hardy-Weinberg $\left(\mathrm{HW} ; F_{I S}=\right.$ 0 ) equilibrium was assumed in the absence of empirical $F_{I S}$ values. As reported by Goodwin et al. (16), due to an error in the $\mathrm{Nm}$ calculations with diploid dominant data in POPGENE version 1.21 , the program used the haploid formula $0.5\left(1-G_{S T} / G_{S T}\right)$ to calculate $N m$ instead of the diploid formula $0.25\left(1-G_{S T} / G_{S T}\right)$. Correction of the $N m$ value was performed manually by dividing the $\mathrm{Nm}$ value calculated by POPGENE by $2 . \mathrm{Nm}$ values were interpreted according to Porter (30): between species, $\mathrm{Nm}$ values greater than or near 1 indicate constant gene flow among populations; values between 0.5 and 1 indicate that gene flow is weak but permits exchange of favorable genes; and values below 0.5 indicate the groups are almost or fully genetically isolated. In addition, null allele frequencies and average heterozygosities were estimated as described by Lynch and Milligan (21). Chi-square analyses were performed to determine differences in allele frequencies among populations.

Sequence analysis. Sequences of the ITSs and the $5.8 \mathrm{~S}$ unit of the ribosomal DNA and partial sequences of the coxII gene and the adjacent intergenic spacer (between coxI and II) of selected isolates were analyzed. Sequences were generated using an ABI Prism Big Dye version 3.1 (Applied Biosystems) sequencing kit and resolved in an ABI Prism 3100 capillarity sequencing system at the Microbial Properties Research Unit of the National Center for Agricultural Utilization Research (U.S. Department of Agriculture-Agricultural Research Service [USDA-ARS], Peoria). Sequences of the ITS region (ITS1, 5.8S ribosomal RNA gene, and ITS2, complete sequence) of 27 P. irregulare s.l. isolates (Table 1) were obtained using primers ITS1 and ITS4 as described in Moorman et al. (26). The selected P. irregulare s.l. isolates were distributed along the AFLP tree and were considered representatives of the genetic diversity of the sample. The ITS sequence of a P. irregulare neotype at the CBS collection (CBSnr 733.94) was provided by C. A. Lévesque (GenBank accession no. AY598702) and was included in our analysis. Additionally, sequences from nine isolates representing the four $P$. irregulare clades proposed by Matsumoto et al. (24), plus one isolate each of $P$. sylvaticum and one of $P$. spinosum from the same study, were obtained from GenBank (Table 1). The sequences were aligned using Clustal X (35) and manually edited for alignment errors. Sequence analysis was performed with parsimony and distance methods using PAUP version 4.0b 10. Parsimony analysis was performed using a heuristic search with random addition of sequences, saving multiple most parsimonious trees. Genetic distances were estimated using the uncorrected- $p$ measure, and tree reconstruction was performed using the NJ algorithm. ITS sequences of $P$. spinosum and
$P$. sylvaticum were used as outgroups. Bootstrap analysis with 1,000 repetitions was performed to estimate the support of internal branches. The data matrix was deposited in TreeBASE (accession no. S1336-M2351).

Partial sequences of the cytochrome oxidase (cox) II gene and spacer region (513 bp of the $3^{\prime}$ end of the coxII gene and $141 \mathrm{bp}$ of the adjacent spacer region between the coxI and II genes) from 28 isolates of $P$. irregulare, 16 from AFLP defined clade IR-I, and 12 from clade IR-II were obtained from polymerase chain reaction products generated using primers FM 35 (5'-CAGAACCTTGGCAATTAGG-3') and FM 52 (5'-GTTGTGCTAATTCCATTCTAA-3') (22), $10 \mu \mathrm{M}, 1.0 \mu \mathrm{l}$ each, in $50-\mu \mathrm{l}$ reactions $(5 \mu \mathrm{l}$ of buffer $[0.5 \mathrm{M} \mathrm{KCl}, 0.1 \mathrm{M}$ Tris- $\mathrm{HCl}, \mathrm{pH} 8.3$, and $0.25 \mathrm{mM}$ $\mathrm{MgCl}_{2}$ ], $5 \mu \mathrm{l}$ of $10 \times \mathrm{dNTP}$ mix containing $2 \mathrm{mM}$ each, $0.1 \mu \mathrm{l}$ of Taq polymerase, and $27.9 \mu \mathrm{l}$ of $\mathrm{H}_{2} \mathrm{O}$ ). Sequences of the forward and reverse strands of the gene were obtained and used in the final alignment. Cycling parameters were those described by Martin (22). Cox sequences of two isolates of P. irregulare (ATCC 96201 and 1987-68) and one sequence each of P. spinosum (79-4) and P. sylvaticum (ATCC 96946) were provided by F. Martin (USDA-ARS, Salinas, CA). Sequence analysis was performed as described above for the ITS region with the alignment deposited in TreeBASE (accession no. S1336-M2352).

Fungicide sensitivity. Forty-eight representative isolates were tested for resistance to either metalaxyl or its enantiomer mefenoxam. Isolates were grown on corn meal agar (CMA) amended with the fungicide $(100 \mu \mathrm{g} / \mathrm{ml})$ and on unamended CMA at $20^{\circ} \mathrm{C}$, for $24 \mathrm{~h}$. Isolates whose growth on fungicide-amended CMA was not slowed by $50 \%$ compared with growth on unamended agar were designated as fungicide-resistant (26).

\section{RESULTS}

Cluster analysis of AFLP data. Three hundred thirty-eight AFLP markers were analyzed. Distance analyses using the UPGMA (Fig. 1) and NJ algorithms generated similar trees (data not included) that differed in some internal branches but agreed in the separation of one 19-isolate cluster from the rest of the sample. This cluster corresponds with previously reported group IR-II (13). The cluster formed by the rest of the sample in the present study contained isolates previously reported as group IRI. This group was further divided into several subgroups that included two to eight isolates, some with good bootstrap support. Because these groups had small sample sizes, we focused on the analysis of the differences between group IR-II and the rest of the sample. Both IR-I and IR-II included isolates from diverse hosts, geographic origins, and years of isolation (Table 1). IR-I included metalaxyl/mefenoxam-sensitive and -resistant isolates, whereas IR-II included metalaxyl/mefenoxam-sensitive isolates only. Although metalaxyl/mefenoxam sensitivity data were obtained for only 11 isolates in IR-II, the probability of finding 11 sensitive isolates in this subgroup at random (based on a binomial probability), if the 44 isolates tested came from the same population, was very small $(P=0.005)$.

Sequence analysis of the ITS region of ribosomal DNA. rDNA-ITS region sequences of 29 isolates representative of the sample diversity were compared with $11 P$. irregulare, one $P$. sylvaticum, and one $P$. spinosum sequence (Table 1) from Matsumoto's study (24). The ITS sequence of the $P$. irregulare neotype (CBSnr 733.94; GenBank accession no. AY598702) was also included to identify $P$. irregulare sensu stricto (s.s. $=$ in the strict sense). Parsimony as well as distance analysis using the NJ algorithm revealed two main groups, well-supported by bootstrap (Fig. 2), that corresponded with the groups revealed by AFLP analysis (IR-I and IR-II). One hundred and five parsimonyinformative sites were found. Variation in amplicon length was found in both groups with IR-I sequences ranging between 936 and $949 \mathrm{bp}$, and IR-II sequences ranging between 936 and $938 \mathrm{bp}$. 
A total of two fixed insertion/deletion mutations and nine fixed nucleotide substitutions separated the two groups. All of our sequences clustered with isolates included in clades I and II by Matsumoto et al. (24), IR-II corresponding with their clade I. Inclusion of the ITS sequence of C. A. Lévesque's P. irregulare neotype revealed that IR-II and Matsumoto's clade I correspond to $P$. irregulare s.s. From here on, the two groups described in this study will be referred to as $P$. irregulare s.s. and Pythium sp. clade IR-I. Isolates from clades III and IV from Matsumoto's study clustered in a completely separate branch, closer to $P$. sylvaticum than to $P$. spinosum, $P$. irregulare s.s., or Pythium sp. clade IR-I.

Cytochrome oxidase II mitochondrial gene and intergenic spacer region. Analysis of partial sequences of the coxII gene and the intergenic spacer region $(651 \mathrm{bp})$ of $28 P$. irregulare isolates representative of the sample diversity ( $P$. irregulare s.s., $n=15$; Pythium sp. clade IR-I, $n=13$ ), plus two sequences of
P. irregulare (ATCC 96201 and 1987-68), and one sequence each of P. spinosum (79-4) and P. sylvaticum (ATCC 96946) provided by F. Martin, revealed 24 parsimony informative characters. Parsimony analysis generated four most parsimonious trees with a score of 62. Trees obtained by parsimony and NJ (Fig. 3) distance analysis displayed a 14-isolate cluster that branched from the main $P$. irregulare group. This cluster included all the isolates from $P$. irregulare s.s. but one, 13-57, which clustered inside $P y$ thium sp. clade IR-I. There were three fixed single nucleotide substitutions between $P$. irregulare s.s. and Pythium sp. clade IR-I (in the coxII gene at nucleotide positions 509 and in the spacer region at bases 585 and 629). The sequence of isolate ATCC 96201 clustered within Pythium sp. clade IR-I, while that of isolate 1987-68 formed an independent branch closer to $P$. spinosum than to $P$. irregulare or $P$. sylvaticum.

AFLP allele frequencies. The allele frequencies of 236 loci were compared. Significant differences in allele frequencies

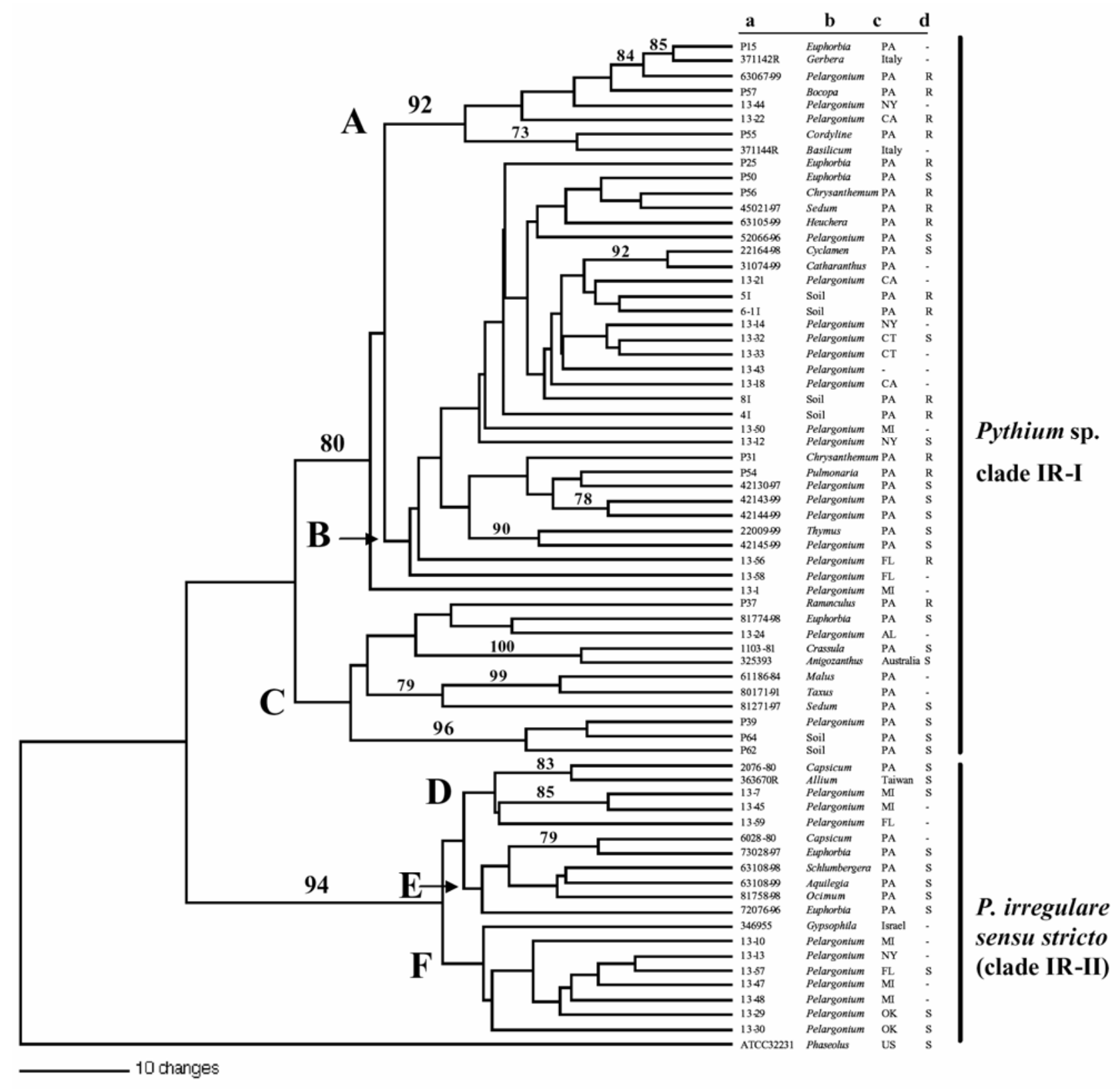

Fig. 1. Unweighted pair-group method with arithmetic average tree of Pythium irregulare depicting Pythium sp. clade IR-I and P. irregulare sensu stricto and their subpopulations (A to C and D to F, respectively) constructed from amplified fragment length polymorphism data. Numbers over branches represent significant ( $>70$ ) bootstrap support values (1,000 repetitions). Isolate information is provided: $\mathrm{a}=$ reference code (Table 1$) ; \mathrm{b}=\mathrm{host} ; \mathrm{c}=$ state or country of origin; and $\mathrm{d}=$ sensitivity to mefenoxam $(\mathrm{R}=$ resistant; $\mathrm{S}=$ sensitive $)$. 
were found between the Pythium sp. clade IR-I and P. irregulare s.s. The number of polymorphic loci in the Pythium sp. clade IR-I was 205 (87\%), while in $P$. irregulare s.s., it was 122 $(52 \%)$. Marker alleles were fixed for one locus and polymorphic at 79 loci in Pythium sp. clade IR-I, but were absent in $P$. irregulare s.s. Conversely, alleles at 16 polymorphic loci from P. irregulare s.s. were absent in the Pythium sp. clade IR-I. The chi-square comparison of allele frequencies indicated that the two clades significantly $(P<0.01)$ differed in the frequencies of $182(77 \%)$ of the alleles. The average heterozygosity of Pythium sp. clade IR-I (0.26) was larger than that of $P$. irregulare s.s. (0.17).

Population structure and gene flow. The AFLP gene diversity statistics indicate some genetic differentiation and restricted gene flow in $P$. irregulare s.l. Nei's gene diversity $(h)$ in $P$. irregulare s.s. was 0.15 (standard deviation $[\mathrm{SD}]=0.184$ ), and in Pythium sp. clade IR-I, it was 0.24 ( $\mathrm{SD}=0.186)$. The average gene diversity within subpopulations $\left(H_{S}\right)$ was $0.20(\mathrm{SD}=0.013)$, while the gene diversity in the total population $\left(H_{T}\right)$ was $0.26(\mathrm{SD}=0.022)$. The coefficient of gene differentiation among subpopulations $\left(G_{S T}\right)$ was 0.24 . The average $N m$ over 236 loci was 0.72 , indicating that the gene flow between P. irregulare s.s. and Pythium sp. clade IR-I is weak but may allow the exchange of favorable genes (30). An $F_{I S}$ value of 1 was used in our calculations to observe the effect of complete inbreeding in the estimation of $G_{S T}$. The estimate of $G_{S T}=0.25$ with inbreeding was slightly larger than the estimate under HW equilibrium. Hence, the absence of empirical $F_{I S}$ values does not affect our estimates of differentiation between clades.

Cluster analysis of P. irregulare s.s. and Pythium sp. clade IR-I from AFLP data (Fig. 1) identified internal groups that were not evident in ITS or coxI-II data (Figs. 2 and 3). Pythium sp. clade IR-I had three main groups (Fig. 1). Group A included isolates resistant to mefenoxam from diverse hosts and locations, although fungicide sensitivity information was available for only half of the isolates; group B included both mefenoxam-sensitive and -resistant isolates, from diverse hosts and locations; and group $\mathrm{C}$ included both mefenoxam-sensitive and -resistant isolates that were collected from diverse hosts in Pennsylvania. P. irregulare s.s. contained mefenoxam-sensitive isolates only, clustering in three main groups. Group D included isolates from diverse hosts and locations; group E included isolates from Pelargonium sp. from diverse locations; and group $\mathrm{F}$ included isolates from diverse hosts from Pennsylvania.

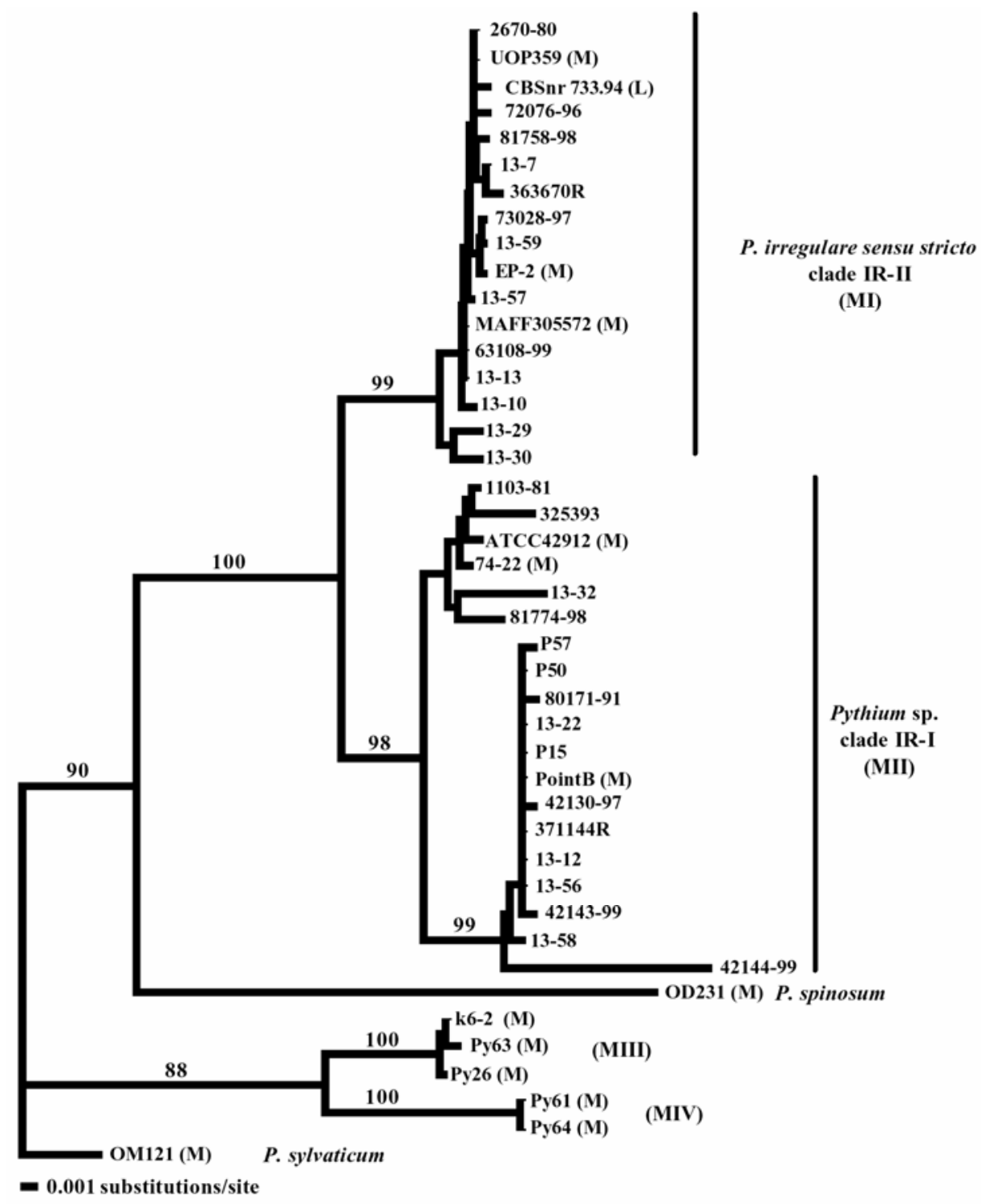

Fig. 2. Pythium irregulare neighbor-joining tree from internal transcribed spacer (ITS) sequences. P. irregulare sensu stricto (clade IR-II) and Pythium sp. clade IR-I are labeled along with clades MI-MIV proposed by Matsumoto et al. (24). Numbers over branches represent significant $(\geq 75)$ bootstrap support values $(1,000$ repetitions). $(\mathrm{M})=$ isolates from Matsumoto et al. $(24) ;(\mathrm{L})=P$. irregulare neotype (CBSnr 733.94). Isolate 13-22 has the same ITS sequence as $P$. regulare (AF492018) and P. cylindrosporum (AY598643). 


\section{DISCUSSION}

Analyses of AFLP fragment data, rDNA-ITS, and the coxII gene and adjacent spacer sequences (whole genome, nuclear and mitochondrial DNA, respectively) from 68 isolates from different hosts and locations suggest that $P$. irregulare s.l. has undergone or is currently undergoing speciation, and includes at least two morphologically similar (cryptic) species. Parsimony and distance analysis of fragment and sequence data identified a distinct 19isolate group that is isolated from the general $P$. irregulare population. The presence of 16 private alleles and absence of 80 AFLP loci, two insertion/deletion mutations and nine nucleotide substitutions in the ITS sequence, and three nucleotide substitutions in the coxII gene and adjacent spacer sequence separate this group from the rest of $P$. irregulare s.l. This distinct group includes the neotype of $P$. irregulare (CBSnr 733.94; GenBank accession no. AY598702), and is thus recognized as $P$. irregulare s.s. The re- maining 49 isolates formed a diverse clade that may or may not include other differentiated groups. Sequence data clearly indicate these isolates do not belong to $P$. irregulare s.s., or the closely related species $P$. sylvaticum and $P$. spinosum. Larger samples are necessary to perform population biology studies in this group. To facilitate the remainder of this discussion, isolates that fit the morphological description of $P$. irregulare s.l. but were not included in $P$. irregulare s.s. by genetic analyses will be referred to as Pythium sp. clade IR-I.

Previous studies have reported genetic differences that suggested $P$. irregulare s.l. may be a complex of cryptic species. White et al. (39) performed a serological profiling of 20 Pythium species. They included five $P$. irregulare isolates that displayed two very distinct profiles. Both principal component analysis and hierarchical cluster analysis of enzyme-linked immunosorbent assay data separated the two groups as completely independent identities. Barr et al. (4) compared the isozyme-based genetic

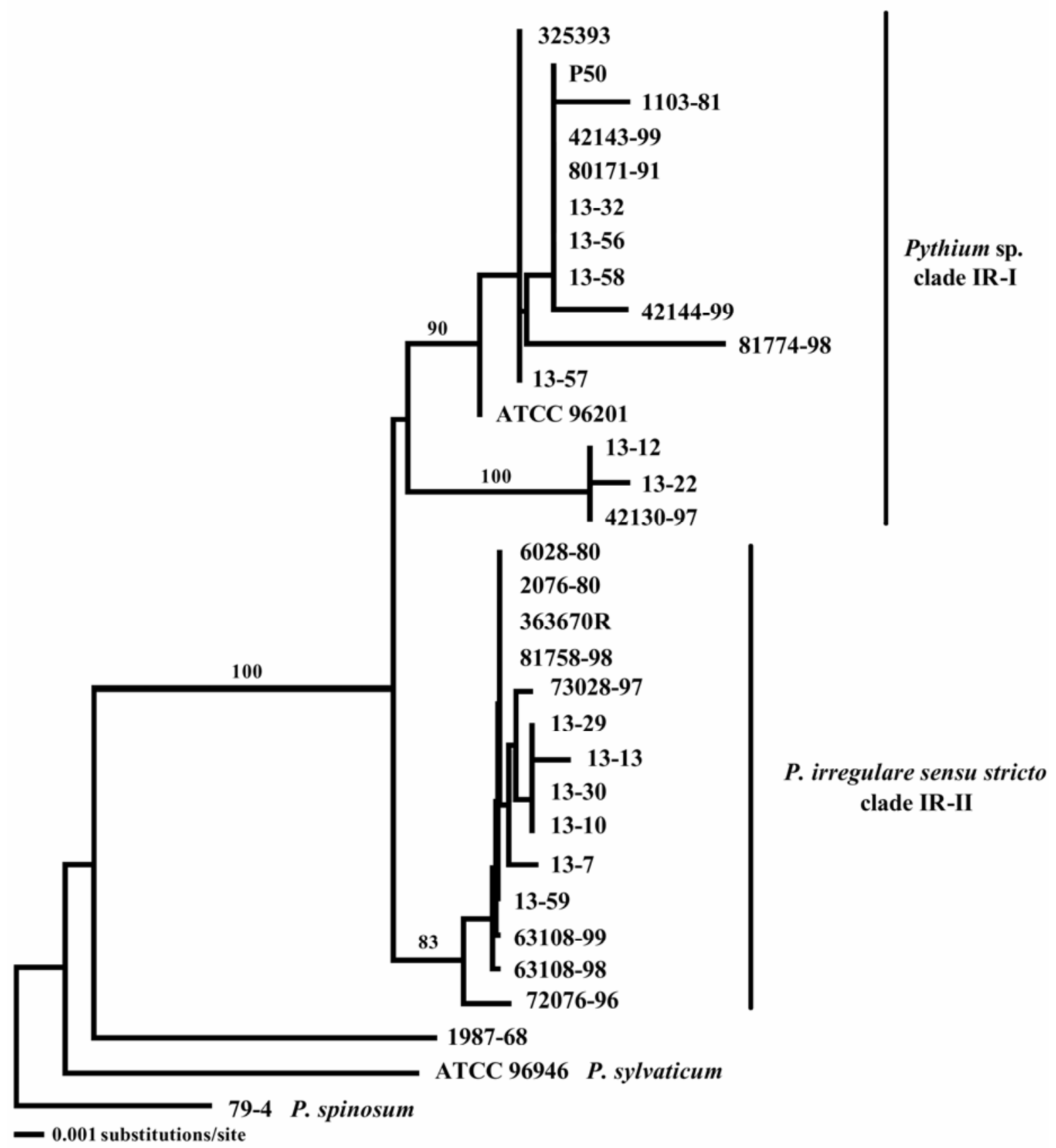

Fig. 3. Pythium irregulare neighbor-joining tree from coxII gene and intergenic spacer (between coxI and II genes) sequences. P. irregulare sensu stricto and Pythium sp. clade IR-I are labeled. Numbers over branches represent significant $(\geq 75)$ bootstrap support values $(1,000$ repetitions $)$. 
diversity of $125 P$. irregulare isolates from diverse locations and hosts around the world. They distinguished 33 multilocus genotypes defined by 11 isozyme loci that grouped into two taxonomically distinct groups. Matsumoto et al. (24) divided 47 isolates morphologically identified as $P$. irregulare into four groups (I to IV) based on ITS-RFLP analysis and RAPD analysis. In their phylogenetic analysis based on sequences of the ITS region, groups I and II, and III and IV clustered more tightly in the same branch, and the genetic divergence between I and II, and III and IV was higher than between either group and P. sylvaticum, suggesting that they may represent two different species. Lévesque and De Cock (19) performed a thorough phylogenetic analysis of the genus Pythium based on ITS region sequences. Their study included $24 P$. irregulare sequences, most of them obtained from GenBank, that formed the same four groups described by Matsumoto et al. (24). Martin (22) performed a phylogenetic analysis of the genus Pythium based on sequence analysis of the cytochrome oxidase II gene. This analysis included five isolates morphologically identified as $P$. irregulare s.l., four of which formed a discrete clade, while the remaining one clustered with $P$. mamillatum. A comparison of the groups identified by these studies with our sample was desirable to obtain a broader perspective of the genetic diversity of $P$. irregulare outside the United States. This could be done by including isolates from those studies or at least DNA sequences from some of their isolates in our analysis. We were able to obtain ITS sequences of isolates from the four groups described by Matsumoto et al. (24) that were deposited by the authors in GenBank. Isolates from group I clustered within $P$. irregulare s.s., and isolates from group II clustered within Pythium sp. clade IR-I. Together, the two studies include isolates of the two species in the $P$. irregulare complex from 11 countries in America, Europe, Asia, and Australia (namely the United States, Canada, Italy, Netherlands, Germany, UK, Poland, Israel, Taiwan, Japan, and Australia) indicating the two species are globally distributed. Matsumoto et al. (24) found slight morphological and growth rate differences between group I and the other three groups. A morphological study is underway to determine if any characters that differentiate $P$. irregulare s.s. from Pythium sp. clade IR-I can be identified. When that study is complete, Pythium sp. clade IR-I will be formally described. In our phylogenetic analysis, Matsumoto's groups III and IV clustered more closely to $P$. sylvaticum than to any $P$. irregulare isolate, supporting their suggestion that groups III and IV represent species other than $P$. irregulare. Lévesque and De Cock (19) provided further evidence that supports groups III and IV from Matsumoto et al. (24) as unique entities, as their phylogenetic analysis separated them from $P$. irregulare and clustered them in a monophyletic clade with $P$. debaryanum, $P$. violae, and $P$. sylvaticum. In addition, two $P$. irregulare sequences from the study by Martin (22) were included in our analysis. One of them (ATCC 96201) clustered within Pythium sp. clade IR-I, while the other (1987-68) formed an independent branch closer to $P$. spinosum than to $P$. irregulare or $P$. sylvaticum. The fact that in both studies isolate 1987-68 clustered closer to species other than $P$. irregulare suggests it may represent some other species. These observations strongly support the conclusion that the morphological description of $P$. irregulare s.l. is broad, and includes at least four discrete clades that may represent distinct phylogenetic species.

Cryptic species are morphologically indistinguishable groups that show other evidence of separation, in this case, an apparent history of very little or no genetic exchange. Cryptic species have been identified in Phytophthora group IV (16) and diverse fungal species such as Stachybotrys chartarum (8), Coccidioides immitis (6), Candida albicans (32,33), and Aspergillus flavus (14,33) among others. Our results suggest that $P$. irregulare s.s. and Pythium sp. clade IR-I are cryptic species capable of exchanging favorable alleles at a fairly low level $(\mathrm{Nm}=0.72)$. Although
P. irregulare s.l. is homothallic and self-fertile, evidence of outcrossing was observed by Harvey et al. $(17,18)$ in populations from a variety of cereal crops, medic (Medicago truncatula) and subclover (Trifolium subterraneum) in Australia. Evidence for outcrossing in the homothallic species P. ultimum and Phytophthora sojae has been previously described (10-12,38). Hybridization and limited gene flow could explain isolate 13-57 (P. irregulare s.s. according to AFLP and ITS sequence data) sharing its coxII gene sequence with the Pythium sp. clade IR-I (cytochrome oxidase being one of a superfamily of proteins that act as the terminal enzymes of respiratory chains, hence a protein with an important function).

It should be considered, nonetheless, that our estimate of $\mathrm{Nm}$ is likely to be an overestimate because of homoplasious AFLP markers, which occur where nonhomologous bands of the same size are scored as the same allele. According to Porter (30), in comparing species "when $\mathrm{Nm}>\sim 1$ then the gene flow is likely to be an important factor promoting genetic similarity between groups; when $\sim 1>\mathrm{Nm}>\sim 0.5$ then gene flow is weak but probably present at levels strong enough to at least permit rapid exchange of favorable genes; when $\sim 0.5>\mathrm{Nm}>0$ then the groups are almost or fully genetically isolated, and the gene flow is likely to be unimportant relative to genetic drift, overestimation notwithstanding." They affirm, nonetheless, that no test can show that a complete boundary exists. It is not clear what factors may have determined the separation of $P$. irregulare s.s. from Pythium sp. clade IR-I. Reproductive isolation of the two species is apparent by the fixation of numerous neutral markers in $P$. irregulare s.s. This group had significantly reduced heterozygosity and gene diversity when compared with Pythium sp. clade IR-I. Although host, metalaxyl/mefenoxam use and geographic origin do not seem to be involved, it is feasible that geographic isolation took place during a period of time that allowed the differentiation of $P$. irregulare s.s., followed by extensive dispersion of the new species. This scenario is not strange in agricultural systems where cultural practices impose strong selective pressures on pathogen populations.

Harvey et al. $(17,18)$ compared the genetic diversity among populations of $P$. irregulare s.l. from different hosts and locations in Australia using co-dominant RFLP markers. Their first study (17) identified some population differentiation among allopatric populations from cereals and concluded that genetic drift and geographic isolation could be responsible for their genetic differences. They estimated a mean genetic differentiation $\left(G_{S T}\right)$ of 0.54 for 29 loci across seven populations. In a second study (18), some genetic differentiation among populations from different hosts was found $\left(G_{S T}=0.21\right)$ without clear evidence of host specificity. They observed, however, that populations from fields where hosts were grown in annual rotation displayed more genetic diversity than populations from long-term medic pastures, which had been regenerating annually for many years. Unfortunately, due to differences in the sampling scale and analytic methods between their research and the present study, comparisons of genetic diversity parameters were difficult. They collected samples exclusively from Australia and compared populations defined by location and host, paying more attention to the differences among those populations than to the overall genetic differentiation within the species. The value they estimated for the mean genetic differentiation $\left(G_{S T}\right)$ in their first study is approximately double the amount estimated in the present study, which could be attributed to the use of co-dominant markers and a large sample size. Co-dominant markers are more informative than dominant markers (21) because they allow the identification of alternative alleles, as well as heterozygote genotypes, which can be compensated for when working with dominant markers by increasing the sample size and the number of loci analyzed. In the present study, those factors were considered. Nonetheless, it is possible that our $G_{S T}$ may be an underestimation of the actual genetic differentiation between 
the two species in P. irregulare s.l. caused by the limited information provided by AFLP dominant markers.

The degree of potential sexual fertility between the two groups described here remains unknown, but the high level of genetic divergence between them is consistent with a historical lack of interbreeding. Further genetic analyses, including hybridization studies will provide useful information about the interaction between these species and the nature of their genetic barriers.

An interesting observation was the absence of metalaxyl/ mefenoxam resistance in the sample of $P$. irregulare s.s. isolates tested. It is feasible that the low genetic variability in $P$. irregulare s.s. reduces its potential for developing fungicide-resistant genotypes. Mefenoxam/metalaxyl resistance has been detected in $P$. cylindrosporum, $P$. dissotocum, $P$. heterothallicum, $P$. splendens, $P$. ultimum, and $P$. aphanidermatum (26), as well as in other oomycete species, such as Phytophthora infestans (15), Phytophthora erythroseptica (34), and Plasmopara halstedii (2).

Recently, Masih and Paul (23) described $P$. regulare as a new species closely related to $P$. irregulare, based on a single isolate from the Canary Islands with $100 \%$ of its oogonia bearing blunt or digitate spines. The ITS sequence from that isolate (GenBank accession no. AF492018) grouped within Pythium sp. clade IR-I and is not different from some other $P$. irregulare sequences previously reported in GenBank (data not shown). Preliminary morphological data from Pythium sp. clade IR-I show oogonia with variable numbers of spines, some carrying none (data not shown), which fits the description of $P$. irregulare but not of $P$. regulare. Because $P$. regulare was defined by one morphological character of a single isolate and its ITS sequence is identical to those of some Pythium sp. clade IR-I isolates (i.e., isolates 1322 [GenBank accession no. AY907903] and 42143-99 [GenBank accession no. AY907897] among others), the validity of this species is questioned. The ITS region sequence of the ex-type isolate of P. cylindrosporum (29) (CBS 218.94, GenBank accession no. AY598643) is also identical to the sequences of $P$. regulare (19) and Pythium sp. clade IR-I; morphologically, however, this species is remarkably different from either of them, with characteristic oogonia that measure up to $200 \mu \mathrm{m}$. As remarked by Lévesque and De Cock (19), the similarities between the ITS sequences of these species are surprising considering their morphological differences. Hence, morphological as well as molecular comparisons between these species are necessary to clarify their identities and phylogeny.

Further analyses are needed to fully characterize $P$. irregulare s.l. To achieve a better understanding of the population biology of each of the species within the complex, larger samples, collected over a period of time, at selected locations and facilities need to be analyzed.

\section{ACKNOWLEDGMENTS}

We thank S. Goodwin for reviewing earlier versions of this paper; M. Milgroom for invaluable comments on the final manuscript; C. A. Lévesque and F. Martin for providing some of the DNA sequences used in our analysis; J. Molineros for writing the SAS program to align AFLP fragments; R. Lease for technical assistance in the first stages of this project; J. Yánez for preliminary work on the morphology of P. irregulare s.l.; and K. O'Donnell for sequencing several samples. This investigation was funded by the American Floral Endowment, the Fred C. Gloeckner Foundation, the USDA-ARS Floriculture and Nursery Crops Research Initiative, and in part, under a grant with the Pennsylvania Department of Health using Tobacco Settlement Funds. The Department specifically disclaims responsibility for any analyses, interpretations, or conclusions.

\section{LITERATURE CITED}

1. Aegerter, B. J., Greathead, A. S., Pierce, L. E., and Davis, R. M. 2002. Mefenoxam-resistant isolates of Pythium irregulare in an ornamental greenhouse in California. Plant Dis. 86:692.
2. Albourie, J. M., Tourvieille, J., and De Labrouhe, D. T. 1998. Resistance to metalaxyl in isolates of the sunflower pathogen Plasmopara halstedii. Eur. J. Plant Pathol. 104:235-242.

3. Bailey, A. M., Mitchell, D. J., Manjunath, K. L., Nolasco, G., and Niblett, C. L. 2002. Identification to the species level of the plant pathogens Phytophthora and Pythium by using unique sequences of the ITS1 region of ribosomal DNA as capture probes for PCR ELISA. FEMS Microbiol. Lett. 207:153-158.

4. Barr, D. J. S., Warwick, S. I., and Desaulniers, N. L. 1997. Isozyme variation, morphology, and growth response to temperature in Pythium irregulare. Can. J. Bot. 75:2073-2081.

5. Bradshawsmith, R. P., Whalley, W. M., and Craig, G. D. 1991. Interactions between Pythium oligandrum and the fungal foot rot pathogens of peas. Mycol. Res. 95:861-865.

6. Burt, A., Carter, D. A., Koenig, G. L., White, T. J., and Taylor, J. W. 1996. Molecular markers reveal cryptic sex in the human pathogen Coccidioides immitis. Proc. Natl. Acad. Sci. USA 93:770-773.

7. Chen, W., Schneider, R. W., and Hoy, J. W. 1992. Taxonomic and phylogenetic analyses of ten Pythium species using isozyme polymorphisms. Phytopathology 82:1234-1244.

8. Cruse, M., Telerant, R., Gallagher, T., Lee, T., and Taylor, J. W. 2002. Cryptic species in Stachybotrys chartarum. Mycologia 94:814-822.

9. Farr, D. F., Bills, G. F., Chamuris, G. P., and Rossman, A. Y. 1989. Fungi on Plants and Plant Products in the United States. The American Phytopathological Society, St. Paul, MN.

10. Francis, D. M., Gehlen, M. F., and St. Clair, D. A. 1994. Genetic variation in homothallic and hyphal swelling isolates of Pythium ultimum var. ultimum and P. ultimum var. sporangiferum. Mol. Plant-Microbe Interact. 7:766-775.

11. Francis, D. M., and St. Clair, D. A. 1993. Outcrossing in the homothallic Oomycete, Pythium ultimum, detected with molecular markers. Curr. Genet. 24:100-106.

12. Francis, D. M., and St. Clair, D. A. 1997. Population genetics of Pythium ultimum. Phytopathology 87:454-461.

13. Garzón, C. D., Geiser, D. M., and Moorman, G. W. 2005. Diagnosis and population analysis of Pythium species using AFLP fingerprinting. Plant Dis. 89:81-89.

14. Geiser, D. M., Pitt, J. I., and Taylor, J. W. 1998. Cryptic speciation and recombination in the aflatoxin-producing fungus Aspergillus flavus. Proc. Natl. Acad. Sci. USA 95:388-393.

15. Goodwin, S. B. 1996. Widespread distribution and probable origin of resistance to metalaxyl in clonal genotypes of Phytophthora infestans in the United States and western Canada. Phytopathology 86:793-800.

16. Goodwin, S. B., Legard, D. L., Smart, C. D., Levy, M., and Fry, W. E. 1999. Gene flow analysis of molecular markers confirms that Phytophthora mirabilis and P. infestans are separate species. Mycologia 91:796-810.

17. Harvey, P. R., Butterworth, P. J., Hawke, B. G., and Pankhurst, C. E. 2000. Genetic variation among populations of Pythium irregulare in southern Australia. Plant Pathol. 49:619-627.

18. Harvey, P. R., Butterworth, P. J., Hawke, B. G., and Pankhurst, C. E. 2001. Genetic and pathogenic variation among cereal, medic and subclover isolates of Pythium irregulare. Mycol. Res. 105:85-93.

19. Lévesque, C. A., and De Cock, A. W. A. M. 2004. Molecular phylogeny and taxonomy of the genus Pythium. Mycol. Res. 108:1363-1383.

20. Lévesque, C. A., Harlton, C. E., and De Cock, A. W. A. M. 1998. Identification of some oomycetes by reverse dot blot hybridization. Phytopathology 88:213-222.

21. Lynch, M., and Milligan, B. G. 1994. Analysis of population geneticstructure with RAPD markers. Mol. Ecol. 3:91-99.

22. Martin, F. N. 2000. Phylogenetic relationships among some Pythium species inferred from sequence analysis of the mitochondrially encoded cytochrome oxidase II gene. Mycologia 92:711-727.

23. Masih, I., and Paul, B. 2003. Pythium regulare sp. nov., isolated from the Canary Islands, its taxonomy, its region of rDNA, and comparison with related species. Curr. Microbiol. 47:309-313.

24. Matsumoto, C., Kageyama, K., Suga, H., and Hyakumachi, M. 2000. Intraspecific DNA polymorphisms of Pythium irregulare. Mycol. Res. 104:1333-1341.

25. Matthew, J., Hawke, B. G., and Pankhurst, C. E. 1995. A DNA-probe for identification of Pythium irregulare in soil. Mycol. Res. 99:579-584.

26. Moorman, G. W., Kang, S., Geiser, D. M., and Kim, S. H. 2002. Identification and characterization of Pythium species associated with greenhouse floral crops in Pennsylvania. Plant Dis. 86:1227-1231.

27. Moorman, G. W., and Kim, S. H. 2004. Species of Pythium from greenhouses in Pennsylvania exhibit resistance to propamocarb and dual resistance to propamocarb and mefenoxam. Plant Dis. 88:630-632.

28. Nei, M. 1987. Molecular Evolutionary Genetics. Columbia University Press, New York.

29. Paul, B. 1992. Pythium cylindrosporum: A new soil fungi from Germany. Int. J. Mycol. Lichenol. 4:337-345. 
30. Porter, A. H. 1990. Testing nominal species boundaries using gene flow statistics: The taxonomy of two hybridizing admiral butterflies (Limenitis: Nymphalidae). Syst. Zool. 39:131-147.

31. Slatkin, M. 1985. Rare alleles as indicators of gene flow. Evolution 39:53-65.

32. Sullivan, D., Bennett, D., Henman, M., Harwood, P., Flint, S., Mulcany, F., Shanley, D., and Coleman, D. 1993. Oligonucleotide fingerprinting of isolates of Candida species other than C. albicans and of atypical Candida species from human immunodeficiency virus-positive and AIDS patients. J. Clin. Microbiol. 31:2124-2133.

33. Taylor, J. W., Geiser, D. M., Burt, A., and Koufopanou, V. 1999. The evolutionary biology and population genetics underlying fungal strain typing. Clin. Microbiol. Rev. 12:126-146.

34. Taylor, R. J., Salas, B., Secor, G. A., Rivera, V., and Gudmestad, N. C. 2002. Sensitivity of North American isolates of Phytophthora erythroseptica and Pythium ultimum to mefenoxam (metalaxyl). Plant Dis. 86:797-802.
35. Thompson, J. D., Gibson, T. J., Plewniak, F., Jeanmougin, F., and Higgins, D. G. 1997. The ClustalX windows interface: Flexible strategies for multiple sequence alignment aided by quality analysis tools. Nucleic Acids Res. 24:4876-4882.

36. Van Der Plaats-Niterink, A. J. 1981. Monograph of the genus Pythium. Vol. 21, Studies in Mycology. Centraal Bureau Voor Schimmelscultures, Baarn, The Netherlands.

37. Waterhouse, G. M. 1968. The genus Pythium. Diagnoses (or descriptions) and figures from the original papers. Mycol. Pap. 110:1-50.

38. Whisson, S. C., Drenth, A., Maclean, D. J., and Irwin, J. A. G. 1994. Evidence for outcrossing in Phytophthora sojae and linkage of a DNA marker to two avirulence genes. Curr. Genet. 21:77-82.

39. White, J. G., Lyons, N. F., Wakeham, A. J., Mead, A., and Green, J. R. 1994. Serological profiling of the fungal genus Pythium. Physiol. Mol. Plant Pathol. 44:349-361. 